\title{
The Role of Sulphonic and Phosphoric Pendant Groups on the Diffusion of Monovalent Ions in Polyelectrolyte Membranes: A Molecular Dynamics Study
}

\author{
Ismail Abdulazeez ${ }^{1, *} \mathbb{C}$, Billel Salhi ${ }^{1}$, Nadeem Baig ${ }^{1}\left(\mathbb{D}\right.$ and Qing Peng ${ }^{2,3,4, *}$ \\ 1 Interdisciplinary Research Center for Membranes and Water Security, King Fahd University of Petroleum and \\ Minerals, Dhahran 31261, Saudi Arabia; billel@kfupm.edu.sa (B.S.); nadeembaig@kfupm.edu.sa (N.B.) \\ 2 Physics Department, King Fahd University of Petroleum and Minerals, Dhahran 31261, Saudi Arabia \\ 3 KACARE Energy Research and Innovation Center at Dhahran, Dhahran 31261, Saudi Arabia \\ 4 Hydrogen and Energy Storage Center, King Fahd University of Petroleum and Minerals, \\ Dhahran 31261, Saudi Arabia \\ * Correspondence: ismail.abdulazeez@kfupm.edu.sa (I.A.); qing.peng@kfupm.edu.sa (Q.P.)
}

\section{check for}

updates

Citation: Abdulazeez, I.; Salhi, B.; Baig, N.; Peng, Q. The Role of Sulphonic and Phosphoric Pendant Groups on the Diffusion of

Monovalent Ions in Polyelectrolyte Membranes: A Molecular Dynamics Study. Membranes 2021, 11, 940. https://doi.org/10.3390/ membranes11120940

Academic Editors: Victor V. Nikonenko and Jin-Soo Park

Received: 6 November 2021

Accepted: 26 November 2021

Published: 28 November 2021

Publisher's Note: MDPI stays neutral with regard to jurisdictional claims in published maps and institutional affiliations.

Copyright: (c) 2021 by the authors. Licensee MDPI, Basel, Switzerland. This article is an open access article distributed under the terms and conditions of the Creative Commons Attribution (CC BY) license (https:/ / creativecommons.org/licenses/by/ $4.0 /)$.

\begin{abstract}
Lithium-ion consumption has risen significantly in recent years due to its use in portable devices. Alternative sources of lithium, which include the recovery from brine using the sustainable and eco-friendly electrodialysis technology, has been explored. This technology, however, requires effective cation-exchange membranes that allow the selective permeation of lithium ions. In this study, we have investigated, via molecular dynamics simulations, the role of the two common charged groups, the sulfonic and the phosphoric groups, in promoting the adsorption of monovalent ions from brine comprising $\mathrm{Li}^{+}, \mathrm{Na}^{+}, \mathrm{Mg}^{2+}$, and $\mathrm{Ca}^{2+}$ ions. The analysis of the mean square displacement of the ions revealed that $\mathrm{Li}^{+}$and $\mathrm{Na}^{+}$ions exhibit superior diffusion behaviors within the polyelectrolyte system. The $\mathrm{O}$-atoms of the charged groups bind strongly with the divalent ions $\left(\mathrm{Mg}^{2+}\right.$ and $\left.\mathrm{Ca}^{2+}\right)$, which raises their diffusion energy barrier and consequently lowers their rate of permeation. In contrast, the monovalent ions exhibit weaker interactions, with $\mathrm{Na}^{+}$being slightly above $\mathrm{Li}^{+}$, enabling the permeation of $\mathrm{Li}^{+}$ions. The present study demonstrates the role of both charged groups in cationexchange membranes in promoting the diffusion of $\mathrm{Li}^{+}$and $\mathrm{Na}^{+}$ions, and could serve as a guide for the design of effective membranes for the recovery of these ions from brine.
\end{abstract}

Keywords: lithium-ion recovery; brine; polyelectrolyte membrane; electrodialysis; MD simulation

\section{Introduction}

The advent of green energy-storage devices, such as lithium-ion batteries (LIBs), which are gradually phasing out the existing lead-acid batteries, nickel-cadmium batteries, and nickel-metal hydride batteries, has contributed significantly to the technological advancement of the world [1-3]. LIBs have found applications in several portable electronic devices, such as cell phones, camcorders, laptops, and, more recently, in electric cars $[4,5]$. The traditional method of production of lithium-ions is through mining or the acid leaching of lithium aluminum inosilicates, otherwise known as spodumene, $\mathrm{LiAl}\left(\mathrm{SiO}_{3}\right)_{2}$ [6]. Lithium metals with high purity (99.50-99.99\%) have also been produced at high temperatures by the electrowinning of molten eutectic LiCl-KCl salts $[7,8]$. These technologies are, however, energy-intensive, capital-intensive, and often result in the production of non-ecofriendly side products. Sodium-ion batteries (SIBs) have also emerged as promising substitutes for LIBs, due to the similarity in their valence shell chemistry [9-11]. In addition, sodium is cheap, non-toxic, and relatively abundant, compared to lithium. While research attention is gradually shifting to the development of SIB technology, it is critical to continue to find alternative sources of the metal ions for the sustainability of these technologies.

Electrodialysis (ED) is a membrane-desalination technology that utilizes ion-exchange membranes to transport ions under the influence of an applied electric potential [12-14]. 
While this technology is used mainly for water purification, it has the potential for the recovery of lithium ions from brine, especially since most brine contains, in addition to $\mathrm{Na}^{+}$ ions, an abundance of cations, such as $\mathrm{Ca}^{2+}, \mathrm{Mg}^{2+}, \mathrm{K}^{+}$, and $\mathrm{L}^{\mathrm{i+}}$ ions [15-18]. The core of this technology is, thus, the design of effective monovalent cation-exchange membranes that allow the selective permeation of $\mathrm{Li}+$ ions while rejecting the divalent ions. Typical cation exchange membranes are composed of polyelectrolyte (PE) molecules containing sulfonic acid, phosphoric acid, or carboxylic acid groups [19]. The interaction of the active functional groups and the mobility of the molecular chain of the PE play critical roles in the diffusion of the ions through the membrane. There is, therefore, the need for a careful architecture of the polymeric backbone and the active functional groups, as these affect the overall performance of the cation-exchange membranes.

Molecular simulation is a functional tool in the design of effective polyelectrolytes for the selective permeation of various metal ions. It is reported in various literature as being complementary to the experimental approach, and has the advantages of low-cost and less labor, and yields results with high accuracy. Several reports have documented the use of simulations to investigate the mechanisms of interactions and the diffusion of counterions in polymeric materials [20-24]. The polyelectrolyte-water molecular simulation model proposed by Stevens and Kremer [25,26] revealed that the spatial orientation of PE molecules in aqueous media was non-linear; rather, they appeared coiled, and shrunk with the aggregation of counterions. The nature of the aggregation of the counterions and the effect of the molecular chain length was later reported by Liu et al. [27]. The nature of aggregation of the counterions was also studied by Konieczny et al. [28], and they found that a few counterions were confined around the PE molecules, while others were distributed in the aqueous phase. The role of co-existing counterions, $\mathrm{Ca}^{2+}$ ions, on the distribution of $\mathrm{Na}^{+}$ions around the PE molecules in the aqueous phase was investigated by Molnar et al. [29], and they found that the $\mathrm{Ca}^{2+}$ ions shielded the intrinsic negative charges on the PE molecules, preventing the effective distribution of $\mathrm{Na}^{+}$ions and promoting the shrinkage of the molecules. The interaction of co-existing $\mathrm{Na}^{+}$and $\mathrm{Ca}^{2+}$ ions on polymethacrylic acid-based PE molecules was reported by Huang et al. [30,31]. Their results revealed that the attraction of the carboxylic acid groups towards $\mathrm{Ca}^{2+}$ ions on the PE molecules played a significant role in the geometric size of the PE molecules. Sun et al. [32] recently proposed the PE chain-counterion aqueous solution model for the investigation of the diffusion behavior of $\mathrm{Li}^{+}$and $\mathrm{Mg}^{2+}$ ions on sulfonic and phosphoric acid fixed-charged group PEs. Their results revealed that the interaction of the counterions with the fixed-charged groups determined the diffusion of the ions, and that the sulfonic acid group was ideal for the selective permeation of monovalent ions, such as $\mathrm{Li}^{+}$ions. This model, owing to its remarkable consonance with experimental data as reported by Sun et al. [32], is further explored in this study.

In the present study, we have investigated, using molecular dynamics (MD), simulations of the influence of both the sulfonic and the phosphoric acid fixed-charge groups on the diffusion of $\mathrm{Li}^{+}, \mathrm{Na}^{+}, \mathrm{Ca}^{2+}$, and $\mathrm{Mg}^{2+}$ ions on PE membranes in aqueous media. The nature of the interactions and the mechanism of diffusion of the counterions through the membrane material were fully accounted for. This study revealed the role of both functional groups in promoting the adsorption of monovalent ions, and could serve as a basis for the design of effective ion-exchange membranes for the recovery of $\mathrm{Li}^{+}$and $\mathrm{Na}^{+}$ ions from brine.

\section{Molecular Dynamics Simulations}

\subsection{Model}

The structural backbone of typical cation-exchange membranes generally contains fixed-charge acid groups, mainly the sulfonic, the phosphoric, or the carboxylic acid groups. The present membrane material was constructed by mixing two aromatic moieties containing the sulfonic and the phosphoric groups. Initially, the two monomers, namely, 4-ethylbenzene sulfonate (designated as $\mathrm{M}_{1}$ ) and 4-ethyl-phenyl phosphate (designated 
as $\mathrm{M}_{2}$ ), as presented in Figure $1 \mathrm{a}, \mathrm{b}$, were sketched and geometrically optimized. The two monomers were co-polymerized to form the copolymer 4-[3-(4-phosphonoxy-phenyl)butyl]-benzene sulfonic acid (designated as co- $\mathrm{M}_{1} \mathrm{M}_{2}$ ), with the degree of polymerization of 1, as presented in Figure 1c, using the Block co-polymer command. Thereafter, co$\mathrm{M}_{1} \mathrm{M}_{2}$ was taken as the monomer for the building of the homopolymer $-\left[\mathrm{M}_{1} \mathrm{M}_{2}\right]-20$, with the degree of polymerization of 20, as presented in Figure 1d. All the molecules-the monomers, the copolymer, and the final polyelectrolyte homopolymer-were geometrically optimized using the Condensed-phase Optimized Molecular Potentials for Atomistic Simulation Studies II (COMPASS II) forcefield on the Forcite module. The COMPASS II forcefield was selected because it provided extended coverage of the COMPASS forcefield to polymeric and heterocyclic systems [33]. The metal cations $\mathrm{Li}^{+}, \mathrm{Na}^{+}, \mathrm{Ca}^{2+}$, and $\mathrm{Mg}^{2+}$, and the anion $\mathrm{Cl}^{-}$ions, were built and the respective charges were assigned. The forcefields assigned for the ions were lithium, +1 ion for $\mathrm{Li}^{+}$; sodium, +1 ion for $\mathrm{Na}^{+}$; calcium, +2 ion for $\mathrm{Ca}^{2+}$; magnesium, +2 ion for $\mathrm{Mg}^{2+}$; and chlorine, -1 ion $\mathrm{for}^{-} \mathrm{Cl}^{-}$. The water molecules were modeled and a rigid planar simple-point charge SPC-like water model was obtained $[34,35]$. The forcefield selected for the atoms were h1o, hydrogen-bonded to O, F, and $\mathrm{o} 2^{*}$, oxygen, sp3 in water explicitly for the hydrogen and oxygen atoms, respectively.

(a)

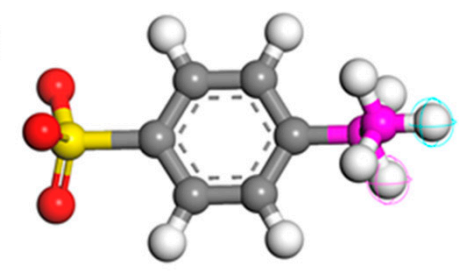

(b)

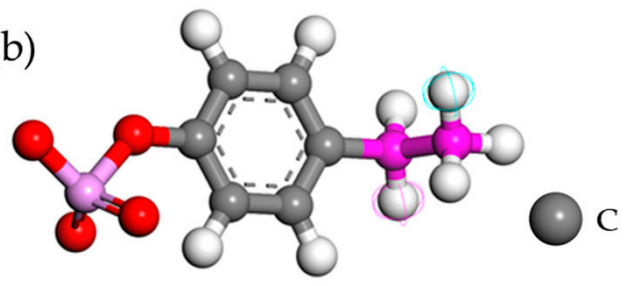

(c)

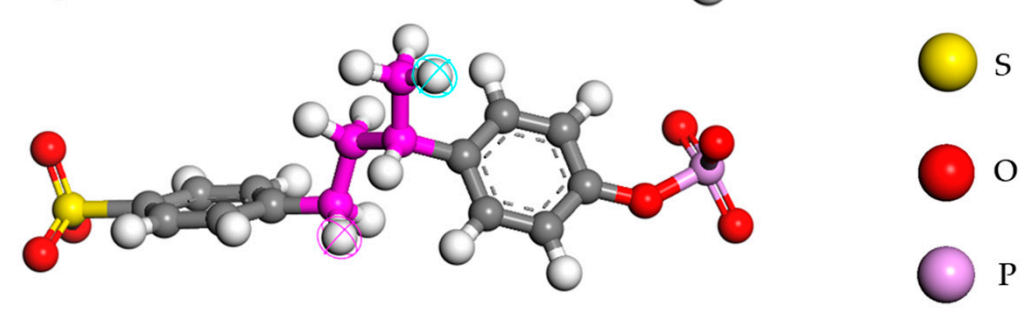<smiles>C1CCCCC1</smiles>

\section{.}

(d)

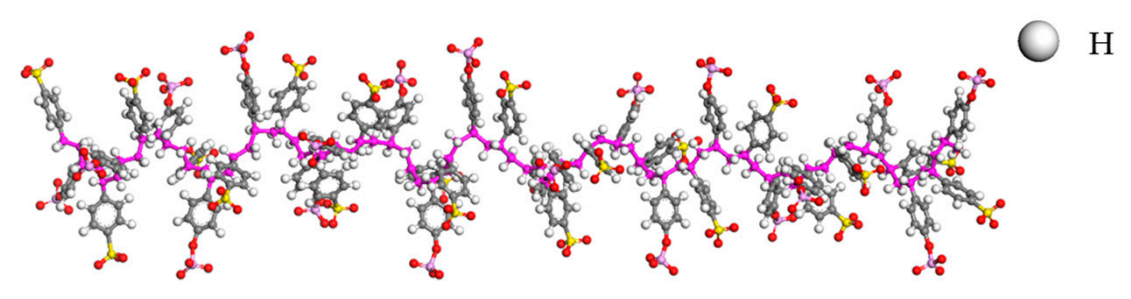

Figure 1. Structural conformations of (a) 4-ethyl benzene sulfonate $\left(\mathrm{M}_{1}\right)$, (b) 4-ethyl-phenyl phosphate $\left(\mathrm{M}_{2}\right)$, (c) 4-[3-(4-phosphonoxy-phenyl)-butyl]-benzene sulfonic acid (co- $\left.\mathrm{M}_{1} \mathrm{M}_{2}\right)$, and (d) the polyelectrolyte chain showing the pendant groups.

\subsection{Construction of Polyelectrolyte-Aqueous System}

The simulation box was built using the amorphous cell module. The polyelectrolytemetal chloride aqueous system was modeled as amorphous in a cubic cell with an edge length of $30 \AA$. The periodic boundary conditions are applied in the three orthogonal directions. The density of the system was set to $1.05 \mathrm{~g} / \mathrm{cm}^{3}$, the temperature to $298 \mathrm{~K}$, and the convergence tolerance quality was set as ultrafine. A typical simulation box consisted of the polyelectrolyte chain with a degree of polymerization 20,20 cations $\left(\mathrm{Li}^{+}, \mathrm{Na}^{+}, \mathrm{Ca}^{2+}\right.$ or $\left.\mathrm{Mg}^{2+}\right)$, a balanced charge of chloride ions (1:1 ratio for the monovalent ions and 1:2 for the divalent ions), and 500 molecules of water. The constructed simulation box was geometrically optimized using the Forcite module and the system maintained electrical neutrality, as presented in Figure 2 for the $\mathrm{PE}-\mathrm{CaCl}_{2}-\mathrm{H}_{2} \mathrm{O}$ system. 


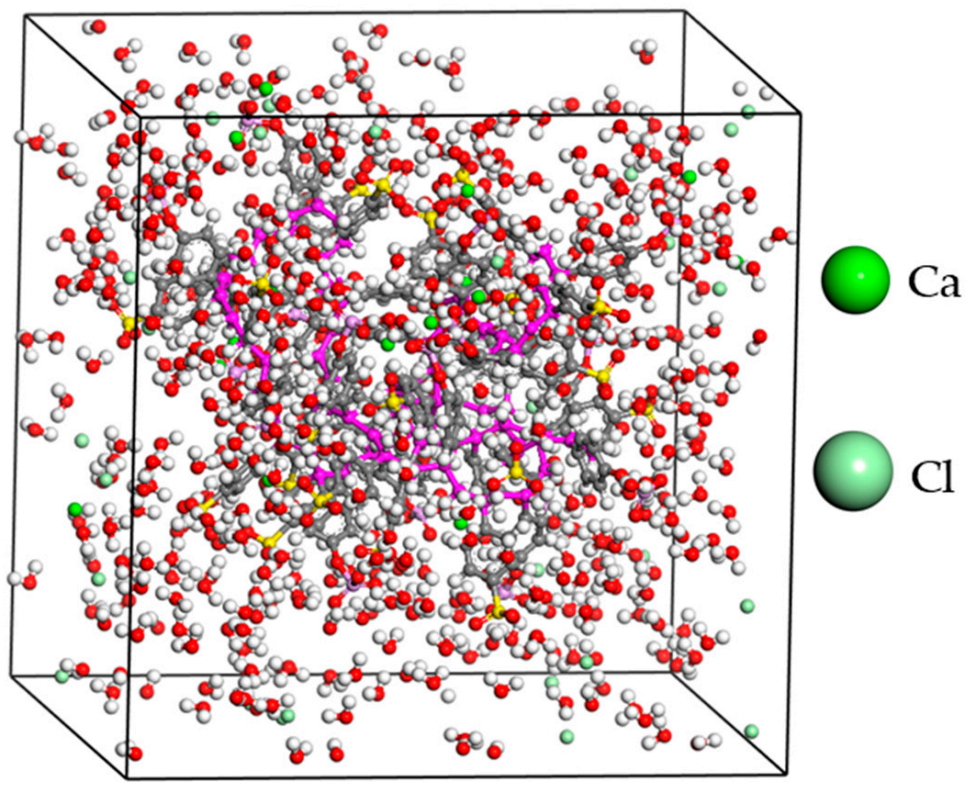

Figure 2. Model of polyelectrolyte- $\mathrm{CaCl}_{2}$-water molecules at $298 \mathrm{~K}$. The purple region represents the polyelectrolyte backbone. All other atoms remain the same as depicted in Figure 1.

\subsection{Molecular Dynamics Simulations}

Molecular dynamics simulations were conducted using the Forcite module. The initial systems were structurally optimized using the congruent gradient, followed by a dynamics simulation on the constant pressure-constant temperature (NPT) ensemble $\left(\mathrm{P}=10^{-4} \mathrm{GPa}, \mathrm{T}=298 \mathrm{~K}\right)$ to stabilize the system with a simulation time of $500 \mathrm{ps}$ and a time step of $0.001 \mathrm{ps}$. The molecules of the polyelectrolyte chain from the last frame generated from the NPT simulation were fixed using the constraints toolbar, and the cations were indicated as set. The system was subjected to the dynamics simulation under the constant volume-constant temperature (NVT) ensemble with a total simulation time of $1.5 \mathrm{~ns}$, and the trace file recording was output at every 5000 steps (5 ps). The starting velocity of the atoms at a given temperature was designated randomly by the Boltzmann distribution, the summation method was atom-based, and a truncation radius of $18.5 \AA$ was chosen for the non-bonded interaction energy. The Particle-Particle Particle-Mesh (PPPM) method of summing up the coulombic electrostatic potential energy was chosen, and the Berendsen constant temperature thermal bath and the constant pressure system was selected for temperature and pressure control. The total energy of the system under the NVT ensemble was determined to confirm the attainment of equilibrium. The total energies of the $\mathrm{CaCl}_{2}, \mathrm{LiCl}, \mathrm{NaCl}$, and the $\mathrm{MgCl}_{2}$ systems fluctuated around 27,000, 21,700, 21,000 , and 30,000 kCal/mol, respectively, as presented in Figure 3.

The diffusion properties of the ions within the polyelectrolytes were determined by estimating the mean square displacement (MSD). The MSD indicates the average separation of all particles from their corresponding initial positions at time $t$ into the motion. The greater the MSD value, the higher the diffusivity of the ions within the system. The MSD at time $t$ in a given ensemble is expressed by the Equation:

$$
\operatorname{MSD}=\frac{1}{N} \sum_{i=1}^{N}\left|x_{i}(t)-x_{i}(0)\right|^{2}
$$

where $N$ represents the number of particles to be averaged, and $x_{i}(0)$ and $x_{i}(t)$ are the initial positions of the $i$ ion and the position of the ion at time $t$, respectively. 


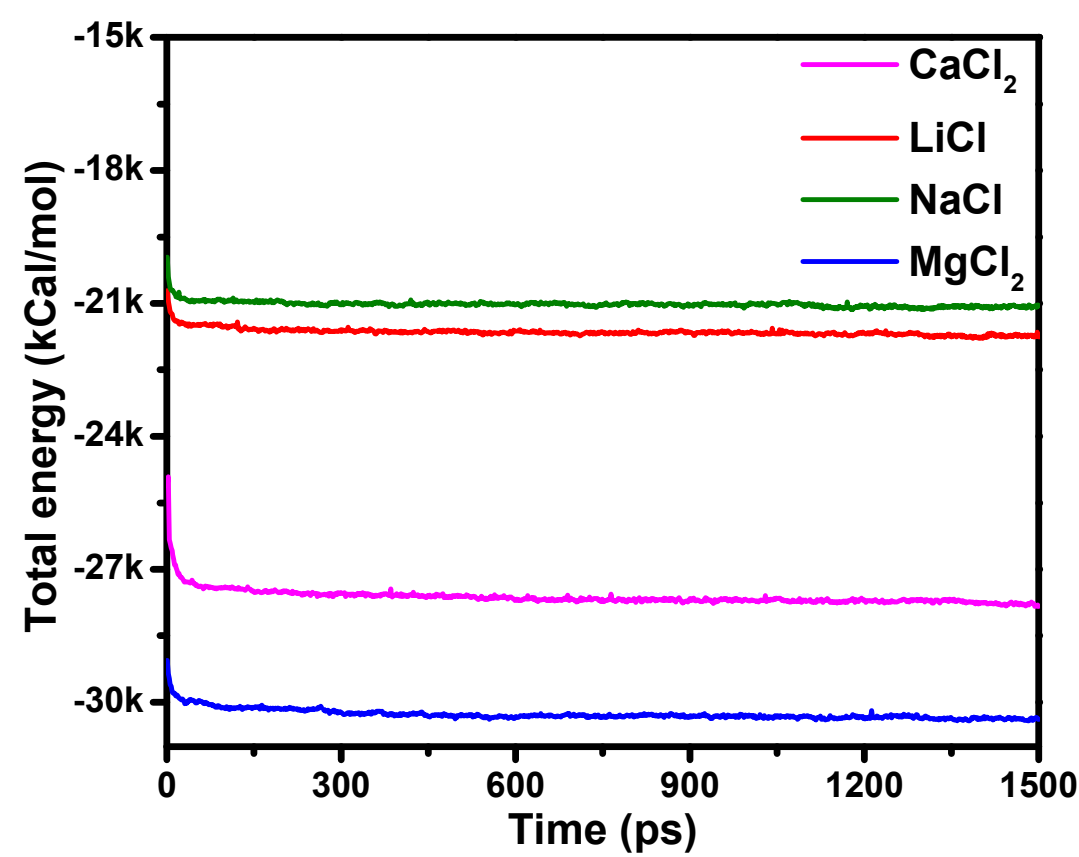

Figure 3. Total energy variations within the NVT ensemble for the polyelectrolyte chain-aqueous system comprising $\mathrm{CaCl}_{2}, \mathrm{LiCl}, \mathrm{NaCl}$, and $\mathrm{MgCl}_{2}$ salts.

The diffusion coefficient of the ions, D, was estimated following the Einstein Equation, as follows:

$$
D=\frac{1}{6} \lim _{t \rightarrow \infty} \frac{d(\mathrm{MSD})}{d t}
$$

A plot of $\log (\mathrm{MSD})$ vs. $\log t$ should give a slope of unity, which, when divided by six, yields the diffusion coefficient of the ions.

The description of the counterion distribution in the vicinity of the fixed-charge groups was estimated by the pair correlation function (PCF), using the expression:

$$
g_{x y}(r)=\frac{V\left[\sum_{i \neq j} \delta\left(r-\left|r_{x i}-r_{y j}\right|\right)\right]}{\left(N_{x} N_{y}-N_{x y}\right) 4 \pi r^{2} d r}
$$

where $x$ and $y$ depict the two interacting systems, $V$ represents the volume of the system, $r$ the separation between them, $N_{x}$ and $N_{y}$ the number of particles of $x$ and $y$, and where $N_{x y}$ stands for the number of similar $x$ and $y$ particles and $r_{x i}$ and $r_{y j}$ for the 3D coordinates of $x$ in $i$ and $y$ in $j$, respectively.

The interaction energies of the counterions towards the fixed-charge groups were estimated as follows:

$$
\Delta E_{\text {int }}=E_{x y}-\left(E_{x}+E_{y}\right)
$$

where $E_{x y}$ represents the total energy of the entire system, and $E_{x}$ and $E_{y}$ are the energies of the PE-aqueous system and the counterions, respectively.

\section{Results and Discussion}

\subsection{The Role of the Fixed-Charged Groups}

A MD simulation was conducted to investigate the counterion migration within the polyelectrolyte membrane material. A system comprising the polyelectrolyte, 500 molecules of water, 20 cations, and charge-balanced $\mathrm{Cl}^{-}$ions were constructed and subjected to NVT dynamic simulation. The diffusion of the ions through the membrane were analyzed by the mean square displacement (MSD) analysis. The MSD- $t$ curves of the polyelectrolyteaqueous system comprising $\mathrm{Li}^{+}, \mathrm{Na}^{+}, \mathrm{Mg}^{2}+$, and $\mathrm{Ca}^{2}+$ ions are presented in Figure 4. The results revealed that the MSD of the monovalent ions $\left(\mathrm{Li}^{+}\right.$and $\left.\mathrm{Na}^{+}\right)$increases linearly 
with time, implying the diffusion of these ions within the polyelectrolyte system. The divalent ions $\left(\mathrm{Mg}^{2+}\right.$ and $\left.\mathrm{Ca}^{2+}\right)$, in contrast, exhibited a relatively stronger interaction with the charged groups on the polyelectrolyte promoted by their effective nuclear charges. Compared to the previous report on isolated sulfonic and phosphoric fixed-charge systems [32], the present polyelectrolyte-aqueous system comprising both functional groups on the polyelectrolyte chain exhibited a weaker attraction for the monovalent ions, resulting in higher MSD values. This could serve as a strategy for the selective permeation of the monovalent ions during recovery from a mixture of all the ions, such as in brine.

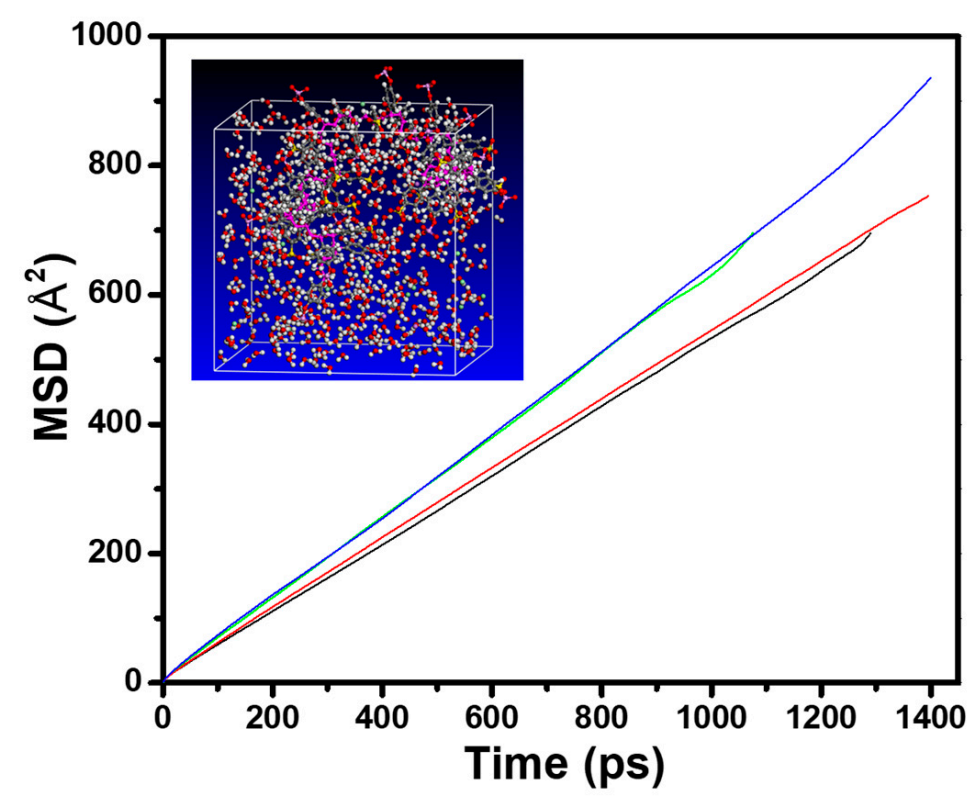

Figure 4. Mean square displacement as a function of time (MSD- $t$ curves) of $\mathrm{Li}^{+}$(blue), $\mathrm{Na}^{+}$(green), $\mathrm{Mg}^{2+}$ (red), and $\mathrm{Ca}^{2+}$ (black) ions in aqueous polyelectrolyte systems. All the atoms remain the same as depicted in Figure 1.

\subsection{Diffusion of Counterions in Aqueous Media}

The role of the polyelectrolyte chain on the diffusion of the metal ions was further investigated by carrying out MD simulations in an aqueous system without the polyelectrolyte. The simulation box in Figure 5a-d consisted of 2500 molecules of $\mathrm{H}_{2} \mathrm{O}, 50$ cations, and a balanced charge of $\mathrm{Cl}^{-}$ions to maintain electrical neutrality. The density of the aqueous system was set to $1.05 \mathrm{~g} / \mathrm{cm}^{3}$ while the other simulation conditions were maintained as before. The mean square displacement as a function of time (MSD- $t$ ) curves of the NVT simulation (Figure 5e) revealed that the MSD of all the cations increased linearly with time and followed the order $\mathrm{Na}^{+}>\mathrm{Li}^{+}>\mathrm{Ca}^{2+}>\mathrm{Mg}^{2+}$, in accordance with their hydration radii [36]. The $\log (\mathrm{MSD})$ vs. $\log (t)$ curve for the $\mathrm{Li}^{+}$ions (Figure $5 \mathrm{f}$ ) and for the other ions (Supplementary Materials) yielded linear fits in all cases, with slopes of 1.0176, 1.0216, 1.0140, and 1.0154 (almost unity) for $\mathrm{Li}^{+}, \mathrm{Na}^{+}, \mathrm{Mg}^{2+}$, and $\mathrm{Ca}^{2+}$ ions, respectively, suggesting that the migration of the ions in aqueous solution occurs predominantly through the diffusion process. The corresponding diffusion coefficients, $\mathrm{D}$, of the ions were calculated as $1.696 \times 10^{-9}, 1.702 \times 10^{-9}, 1.690 \times 10^{-9}$, and $1.692 \times 10^{-9} \mathrm{~m}^{2} / \mathrm{s}$ for $\mathrm{Li}^{+}, \mathrm{Na}^{+}, \mathrm{Mg}^{2+}$, and $\mathrm{Ca}^{2+}$ ions, respectively. While the simulated $\mathrm{D}$ values did not yield exactly the same results as the actual D values of the ions in aqueous media [37], the simulated values are of almost the same magnitude as the actual values, and are consistent with the size-charge correlation, in the order $\mathrm{Mg}^{2+}<\mathrm{Ca}^{2+}<\mathrm{Li}^{+}<\mathrm{Na}^{+}$. 
(a)

(c)

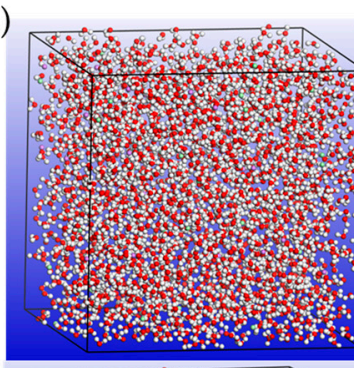

(b)
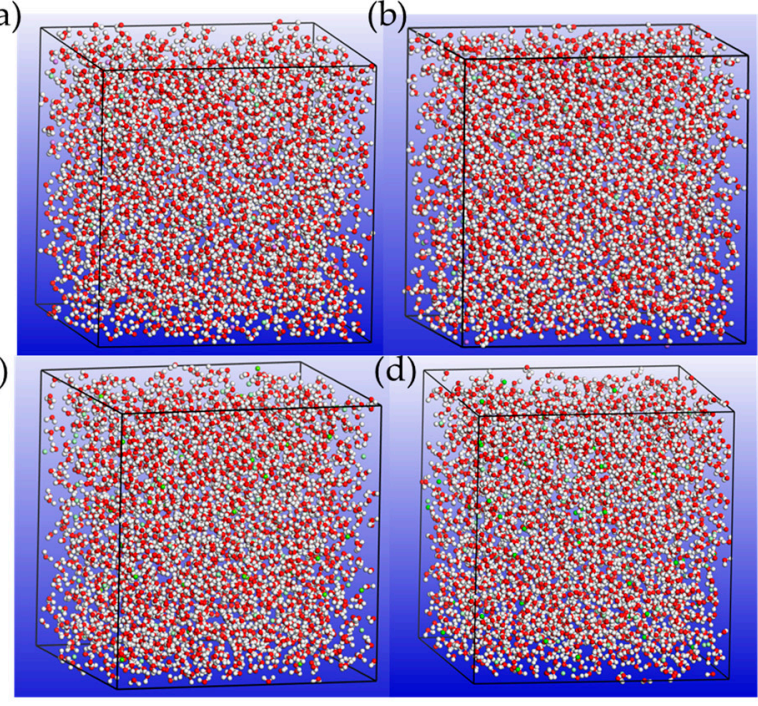
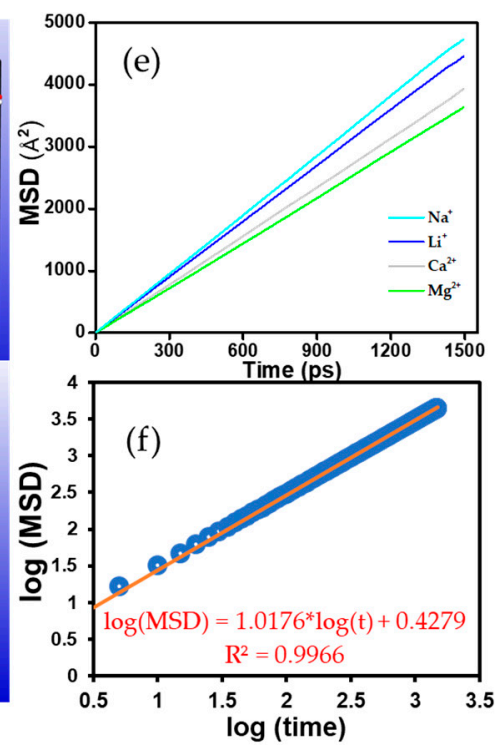

Figure 5. Representative simulation model of the counterions-aqueous system (a) $\mathrm{Li}^{+},(\mathbf{b}) \mathrm{Na}^{+}$, (c) $\mathrm{Mg}^{2+}$, and (d) $\mathrm{Ca}^{2+}$ ions at $298 \mathrm{~K}$. The MSD- $t$ curve of all the ions-blue $\left(\mathrm{Li}^{+}\right)$, red $\left(\mathrm{Na}^{+}\right)$, black $\left(\mathrm{Mg}^{2+}\right)$, and green $\left(\mathrm{Ca}^{2+}\right)$-are shown in (e), whereas the $\log (\mathrm{MSD})$ vs. $\log (\mathrm{t})$ curve for $\mathrm{Li}^{+}$ions is shown in (f). All other atoms remain the same as depicted in Figure 1.

\subsection{Interaction of Co-Existing Ions with the Polyelectrolyte Chain}

The interaction of the polyelectrolyte chain with co-existing ionic systems $\mathrm{Li}^{+} / \mathrm{Na}^{+}$, $\mathrm{Li}^{+} / \mathrm{Mg}^{2+}$, and $\mathrm{Li}^{+} / \mathrm{Ca}^{2+}$, was further investigated. MD simulations were carried out in an NVT ensemble on a simulation box consisting of a 1:1 ratio for the ions, the polyelectrolyte chain, 500 molecules of $\mathrm{H}_{2} \mathrm{O}$, and a balance of $\mathrm{Cl}^{-}$ions. The simulation conditions remained the same as previously. Figure 6 presents the distribution of $\mathrm{Li}^{+}$ions around the charged groups. Two major peaks were observed in all plots, indicating two major interaction regions in accordance with the ionic hydration shells [38,39]. The sharp peak around $1.05 \AA$ corresponds to a strong electrostatic attraction between the O-atoms of the charged groups and the $\mathrm{Li}^{+}$ions. The second peak at $1.65 \AA$ indicates that two major close-range interactions occur between the O-atoms and the $\mathrm{Li}^{+}$ions. For other peaks at higher separations, $r$ appeared weaker and eventually diminished due to the shielding of the negative charges, possibly by molecules of water, thereby weakening the interactions with $\mathrm{Li}^{+}$ions. The snapshots of the attraction of the counterions towards the $\mathrm{O}$-atoms are presented in Figure 7, and indicate a moderate attraction for the $\mathrm{Li}^{+}$ions, resulting in the effective diffusion of the ions within the membrane material.

\subsection{Interaction of the Polyelectrolyte Chain with $\mathrm{Mg}^{2+} / \mathrm{Li}^{+}$Ions}

The concentration of $\mathrm{Mg}^{2+}$ ions in most brine is often greater than those of $\mathrm{Li}^{+}$ions [40-42]. This results in a competition in the diffusion of the ions during the recovery process. In order to suppress the interference of the $\mathrm{Mg}^{2+}$ ions, it is desired that the polyelectrolyte chain in the membrane material exhibits a high affinity and, consequently, a greater retardation for the competing ions. The interaction of the polyelectrolyte chain with $\mathrm{Mg}^{2+} / \mathrm{Li}^{+}$ ions was investigated in this study to explore the effect of a high concentration of $\mathrm{Mg}^{2+}$ ions on the diffusion of $\mathrm{Li}^{+}$ions. Three PE-aqueous systems were constructed, comprising 5 polyelectrolyte chains, 2500 molecules of $\mathrm{H}_{2} \mathrm{O}, 20 \mathrm{Li}^{+}$ions, 50,100 , and $200 \mathrm{Mg}^{2+}$ ions in the first, second, and third systems, respectively, and a balanced charge of $\mathrm{Cl}^{-}$ions. All other simulation details remained as previously described. The distribution of $\mathrm{Li}^{+}$ions around the charged groups are reflected in Figure 8. Two distinct strong peaks are visible in the curve, similar to those presented in Figure 6. The intensity of the peak at $1.05 \AA$ was strongest when the amount of $\mathrm{Mg}^{2+}$ ions was maintained at 50. This is due to the presence of sufficient charged groups, and the competitive adsorption between the $\mathrm{Mg}^{2+}$ and the 
$\mathrm{Li}^{+}$ions was not substantial. Increasing the $\mathrm{Mg}^{2+}$ ions to 100 , and later to 200, resulted in a decrease in the intensity of the O-Li distribution peak, which occurred as a result of the significant shielding of a considerable amount of $\mathrm{Li}^{+}$ions which are prevented from reaching the electro-adsorption layer of the charged groups. This weakens the interaction with the $\mathrm{Li}^{+}$ions, and promotes their diffusion through the polyelectrolyte. These results suggest that increasing the concentration of the $\mathrm{Mg}^{2+}$ ions enhances the diffusion of $\mathrm{Li}^{+}$ions, making the membrane material suitable for the recovery of $\mathrm{Li}^{+}$ions in brine containing high concentrations of $\mathrm{Mg}^{2+}$ ions.

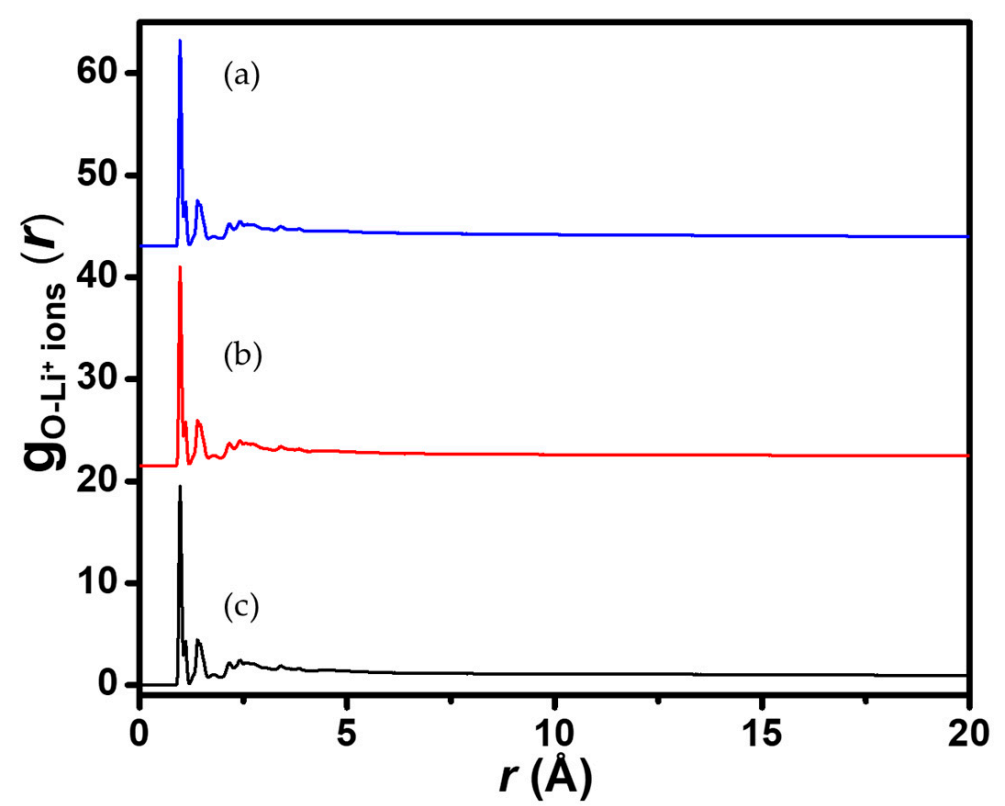

Figure 6. Radial distribution functions of O-atoms in the sulfonic and phosphoric fixed-charge groups to $\mathrm{Li}^{+}$ions in an ensemble comprising $(\mathbf{a}) \mathrm{Li}^{+} / \mathrm{Na}^{+},(\mathbf{b}) \mathrm{Li}^{+} / \mathrm{Mg}^{2+}$, and $(\mathbf{c}) \mathrm{Li}^{+} / \mathrm{Ca}^{2+}$ ions.

(a)

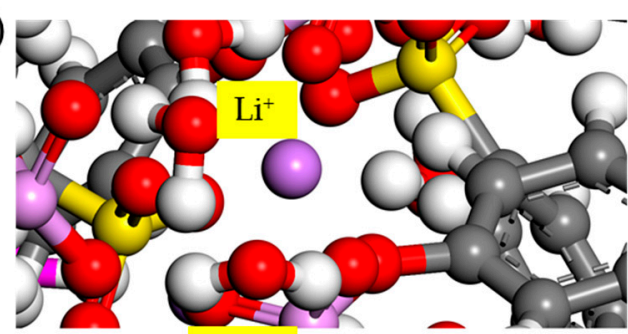

(c)

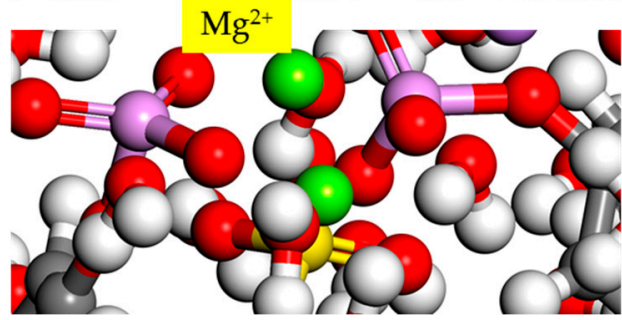

(b)

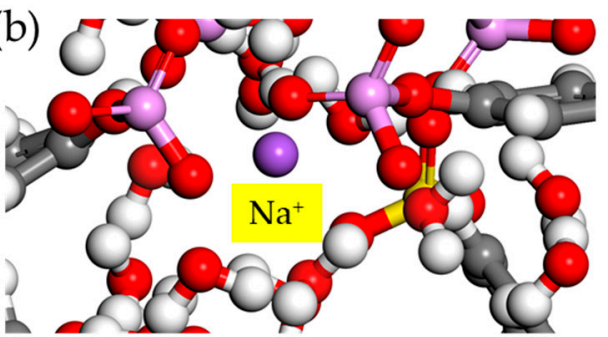

(d)

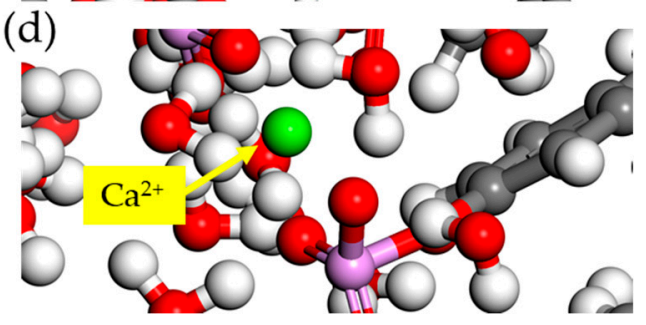

Figure 7. Snapshots of the interactions of $(\mathbf{a}) \mathrm{Li}^{+},(\mathbf{b}) \mathrm{Na}^{+},(\mathbf{c}) \mathrm{Mg}^{2+}$, and (d) $\mathrm{Ca}^{2+}$ ions during an NVT simulation at $298 \mathrm{~K}$. All other atoms remain the same as depicted in Figure 1. 


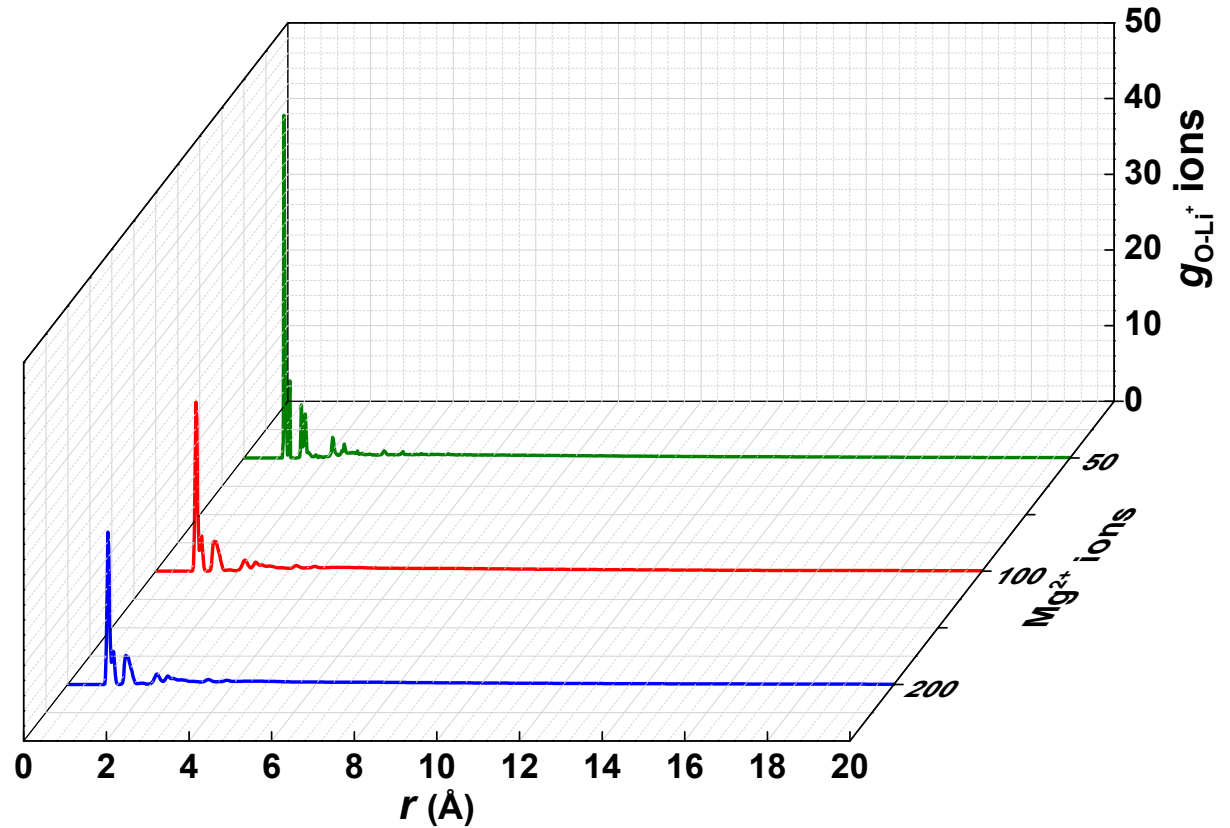

Figure 8. Radial distribution functions of O-atoms in the sulfonic and phosphoric fixed-charge groups to $\mathrm{Li}^{+}$ions in an ensemble comprised of $\mathrm{Mg}^{2+} / \mathrm{Li}^{+}$ions.

The permeability of the ions was further investigated by constructing an ensemble consisting of the polyelectrolyte chain, 500 molecules of $\mathrm{H}_{2} \mathrm{O}, 20$ ions each of $\mathrm{Li}^{+}, \mathrm{Na}^{+}, \mathrm{Mg}^{2+}$, and $\mathrm{Ca}^{2+}$, and a balanced charge of $\mathrm{Cl}^{-}$ions. At the end of the NVT dynamic simulation, the final frame was taken and the spatial position of constraints of the polyelectrolyte chain was removed. The total energy of the system, the energies of the solvated counterions, and the energy of the aqueous polyelectrolyte system were determined following a previously reported method [32]. The interaction energies were calculated using Equation (4) and presented in Figure 9. The polyelectrolyte exhibited a significant attraction for divalent ions $\left(\mathrm{Mg}^{2+}\right.$ and $\left.\mathrm{Ca}^{2+}\right)$, which increased the energy barrier between them, resulting in the lowering of their diffusion characteristics. The order of interaction energies $\left(\mathrm{Mg}^{2+}>\mathrm{Ca}^{2+}>\right.$ $\left.\mathrm{Na}^{+}>\mathrm{Li}^{+}\right)$indicates the selective permeation of monovalent ions through the system.

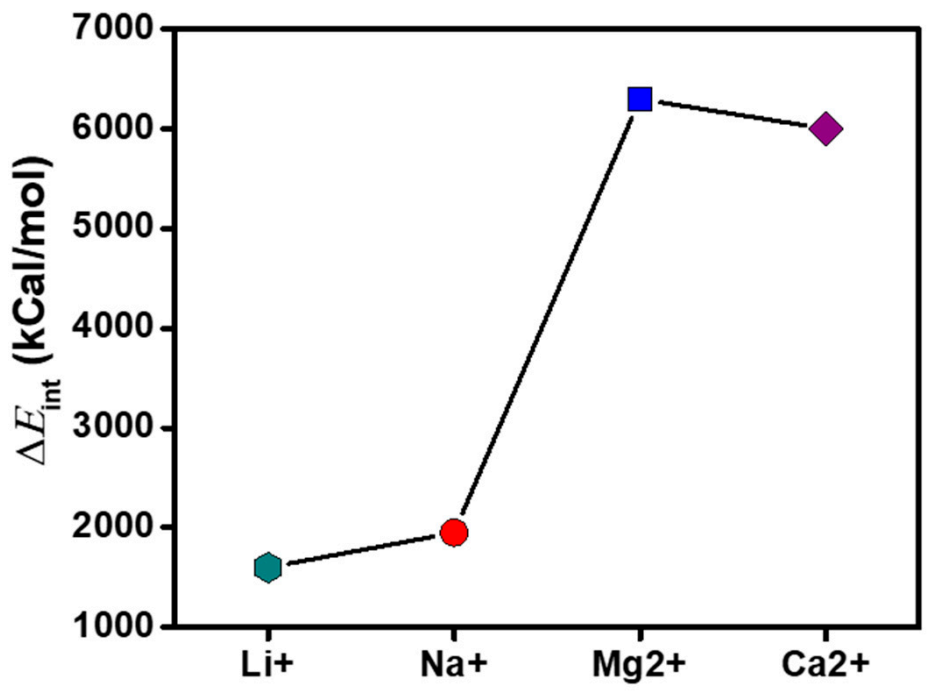

Figure 9. Interaction energy of the counterions towards the sulfonic and phosphoric pendant groups in the polyelectrolyte membrane. 


\section{Conclusions}

We have investigated the diffusion of $\mathrm{Li}^{+}, \mathrm{Na}^{+}, \mathrm{Mg}^{2+}$, and $\mathrm{Ca}^{2+}$ ions in brine through the polyelectrolyte membrane materials containing sulfonic and phosphoric pendant groups by means of molecular dynamics simulations. It was revealed that the O-atoms of the charged groups exhibit stronger attractions for the divalent ions, resulting in a rise in the diffusion energy barrier and, consequently, lowering their diffusion through the membrane material. The analysis of the mean square displacement of the ions revealed that $\mathrm{Li}^{+}$and $\mathrm{Na}^{+}$ions exhibit greater values due to the weak attraction by the charged groups. In the presence of higher concentrations of $\mathrm{Mg}^{2+}$ ions, the radial distribution function of the $\mathrm{O}-\mathrm{Li}$ atoms decreases, suggesting the diffusion of $\mathrm{Li}+$ ions through the polyelectrolyte system. This study demonstrates the role of both the sulfonic and the phosphoric pendant groups in promoting the diffusion of monovalent ions. Our results could serve as a guide for the design of effective cation-exchange membranes for the recovery of $\mathrm{Li}^{+}$and $\mathrm{Na}^{+}$ions from brine.

Supplementary Materials: The following are available online at https:/ / www.mdpi.com/article/ 10.3390/membranes11120940/s1, Figure S1: $\log$ (MSD) vs log t plots of (a) $\mathrm{Mg}^{2+}$, (b) $\mathrm{Ca}^{2+}$ and (c) $\mathrm{Na}^{+}$ions.

Author Contributions: Conceptualization, I.A. and Q.P.; methodology, I.A.; software, I.A.; validation, B.S. and N.B.; resources, I.A.; data curation, I.A.; writing—original draft preparation, I.A. and Q.P.; writing—review and editing, B.S. and N.B.; visualization, Q.P.; supervision, Q.P.; funding acquisition, Q.P. All authors have read and agreed to the published version of the manuscript.

Funding: This research received no external funding.

Institutional Review Board Statement: Not applicable.

Informed Consent Statement: Not applicable.

Data Availability Statement: The raw data generated during this study will be made available by the corresponding authors, without undue reservation, upon request.

Acknowledgments: The authors acknowledge the Deanship of Scientific Research (DSR) at King Fahd University of Petroleum and Minerals for providing the computing resources and for the financial support.

Conflicts of Interest: The authors declare no conflict of interest.

\section{References}

1. Dutta, D.; Kumari, A.; Panda, R.; Jha, S.; Gupta, D.; Goel, S.; Jha, M.K. Close loop separation process for the recovery of Co, Cu, Mn, Fe and Li from spent lithium-ion batteries. Sep. Purif. Technol. 2018, 200, 327-334. [CrossRef]

2. Zhang, W.; Xu, C.; He, W.; Li, G.; Huang, J. A review on management of spent lithium ion batteries and strategy for resource recycling of all components from them. Waste Manag. Res. 2018, 36, 99-112. [CrossRef] [PubMed]

3. Sun, Y.; Zhu, M.; Yao, Y.; Wang, H.; Tong, B.; Zhao, Z. A novel approach for the selective extraction of Li+ from the leaching solution of spent lithium-ion batteries using benzo-15-crown-5 ether as extractant. Sep. Purif. Technol. 2020, 237, 116325. [CrossRef]

4. Ikram, R.; Mohamed Jan, B.; Atif Pervez, S.; Papadakis, V.M.; Ahmad, W.; Bushra, R.; Kenanakis, G.; Rana, M. Recent Advancements of N-Doped Graphene for Rechargeable Batteries: A Review. Crystals 2020, 10, 1080. [CrossRef]

5. Mun, S.C.; Won, J.H. Manufacturing Processes of Microporous Polyolefin Separators for Lithium-Ion Batteries and Correlations between Mechanical and Physical Properties. Crystals 2021, 11, 1013. [CrossRef]

6. Dang, H.; Li, N.; Chang, Z.; Wang, B.; Zhan, Y.; Wu, X.; Liu, W.; Ali, S.; Li, H.; Guo, J.; et al. Lithium leaching via calcium chloride roasting from simulated pyrometallurgical slag of spent lithium ion battery. Sep. Purif. Technol. 2020, 233, 116025. [CrossRef]

7. Zhang, X.; Han, A.; Yang, Y. Review on the production of high-purity lithium metal. J. Mater. Chem. 2020, 8, 22455-22466. [CrossRef]

8. Sato, Y. Electrowinning of Metallic Lithium from Molten Salts. ECS Proc. Vol. 2002, 2002, 771. [CrossRef]

9. Chen, M.; Zhang, Y.; Xing, G.; Tang, Y. Building High Power Density of Sodium-Ion Batteries: Importance of Multidimensional Diffusion Pathways in Cathode Materials. Front. Chem. 2020, 8, 152. [CrossRef] [PubMed]

10. Pandit, B.; Rondiya, S.R.; Dzade, N.Y.; Shaikh, S.F.; Kumar, N.; Goda, E.S.; Al-Kahtani, A.A.; Mane, R.S.; Mathur, S.; Salunkhe, R.R. High Stability and Long Cycle Life of Rechargeable Sodium-Ion Battery Using Manganese Oxide Cathode: A Combined Density Functional Theory (DFT) and Experimental Study. ACS Appl. Mater. Interfaces 2021, 13, 11433-11441. [CrossRef] 
11. Abraham, K.M. How Comparable Are Sodium-Ion Batteries to Lithium-Ion Counterparts? ACS Energy Lett. 2020, 5, $3544-3547$. [CrossRef]

12. Strathmann, H. Electrodialysis, a mature technology with a multitude of new applications. Desalination 2010, 264, 268-288. [CrossRef]

13. Sadrzadeh, M.; Mohammadi, T. Sea water desalination using electrodialysis. Desalination 2008, 221, 440-447. [CrossRef]

14. Gurreri, L.; Tamburini, A.; Cipollina, A.; Micale, G. Electrodialysis Applications in Wastewater Treatment for Environmental Protection and Resources Recovery: A Systematic Review on Progress and Perspectives. Membranes 2020, 10, 146. [CrossRef] [PubMed]

15. Ying, J.; Luo, M.; Jin, Y.; Yu, J. Selective separation of lithium from high Mg/Li ratio brine using single-stage and multi-stage selective electrodialysis processes. Desalination 2020, 492, 114621. [CrossRef]

16. Nie, X.-Y.; Sun, S.-Y.; Sun, Z.; Song, X.; Yu, J.-G. Ion-fractionation of lithium ions from magnesium ions by electrodialysis using monovalent selective ion-exchange membranes. Desalination 2017, 403, 128-135. [CrossRef]

17. Nie, X.-Y.; Sun, S.-Y.; Song, X.; Yu, J.-G. Further investigation into lithium recovery from salt lake brines with different feed characteristics by electrodialysis. J. Membr. Sci. 2017, 530, 185-191. [CrossRef]

18. Nagarale, R.K.; Gohil, G.S.; Shahi, V.K. Recent developments on ion-exchange membranes and electro-membrane processes. Adv. Colloid Interface Sci. 2006, 119, 97-130. [CrossRef]

19. Ran, J.; Wu, L.; He, Y.; Yang, Z.; Wang, Y.; Jiang, C.; Ge, L.; Bakangura, E.; Xu, T. Ion exchange membranes: New developments and applications. J. Membr. Sci. 2017, 522, 267-291. [CrossRef]

20. Ling, C.; Liang, X.; Fan, F.; Yang, Z. Diffusion behavior of the model diesel components in different polymer membranes by molecular dynamic simulation. Chem. Eng. Sci. 2012, 84, 292-302. [CrossRef]

21. Chang, K.-S.; Chung, Y.-C.; Yang, T.-H.; Lue, S.J.; Tung, K.-L.; Lin, Y.-F. Free volume and alcohol transport properties of PDMS membranes: Insights of nano-structure and interfacial affinity from molecular modeling. J. Membr. Sci. 2012, 417, 119-130. [CrossRef]

22. Carrillo, J.-M.Y.; Dobrynin, A.V. Molecular Dynamics Simulations of Polyelectrolyte Adsorption. Langmuir 2007, $23,2472-2482$. [CrossRef]

23. Zhu, Y.-L.; Lu, Z.-Y.; Milano, G.; Shi, A.-C.; Sun, Z.-Y. Hybrid particle-field molecular dynamics simulation for polyelectrolyte systems. Phys. Chem. Chem. Phys. 2016, 18, 9799-9808. [CrossRef]

24. Winkler, R.G.; Gold, M.; Reineker, P. Collapse of Polyelectrolyte Macromolecules by Counterion Condensation and Ion Pair Formation: A Molecular Dynamics Simulation Study. Phys. Rev. Lett. 1998, 80, 3731-3734. [CrossRef]

25. Stevens, M.J.; Kremer, K. Form factor of salt-free linear polyelectrolytes. Macromolecules 1993, 26, 4717-4719. [CrossRef]

26. Stevens, M.J.; Kremer, K. The nature of flexible linear polyelectrolytes in salt free solution: A molecular dynamics study. J. Chem. Phys. 1995, 103, 1669-1690. [CrossRef]

27. Liu, S.; Muthukumar, M. Langevin dynamics simulation of counterion distribution around isolated flexible polyelectrolyte chains. J. Chem. Phys. 2002, 116, 9975-9982. [CrossRef]

28. Konieczny, M.; Likos, C.N.; Löwen, H. Soft effective interactions between weakly charged polyelectrolyte chains. J. Chem. Phys. 2004, 121, 4913-4924. [CrossRef]

29. Molnar, F.; Rieger, J. “Like-Charge Attraction” between Anionic Polyelectrolytes: Molecular Dynamics Simulations. Langmuir 2005, 21, 786-789. [CrossRef] [PubMed]

30. Ju, S.P.; Lee, W.J.; Huang, C.I.; Cheng, W.Z.; Chung, Y.T. Structure and dynamics of water surrounding the poly(methacrylic acid): A molecular dynamics study. J. Chem. Phys. 2007, 126, 224901. [CrossRef] [PubMed]

31. Chung, Y.T.; Huang, C.I. Ion condensation behavior and dynamics of water molecules surrounding the sodium poly(methacrylic acid) chain in water: A molecular dynamics study. J. Chem. Phys. 2012, 136, 124903. [CrossRef]

32. Sun, S.-Y.; Nie, X.-Y.; Huang, J.; Yu, J.-G. Molecular simulation of diffusion behavior of counterions within polyelectrolyte membranes used in electrodialysis. J. Membr. Sci. 2020, 595, 117528. [CrossRef]

33. Sun, H.; Jin, Z.; Yang, C.; Akkermans, R.L.; Robertson, S.H.; Spenley, N.A.; Miller, S.; Todd, S.M. COMPASS II: Extended coverage for polymer and drug-like molecule databases. J. Mol. Model. 2016, 22, 47. [CrossRef] [PubMed]

34. Agarwal, M.; Alam, M.P.; Chakravarty, C. Thermodynamic, Diffusional, and Structural Anomalies in Rigid-Body Water Models. J. Phys. Chem. 2011, 115, 6935-6945. [CrossRef]

35. Ahlström, P.; Wallqvist, A.; Engström, S.; Jönsson, B. A molecular dynamics study of polarizable water. Mol. Phys. 1989, 68, 563-581. [CrossRef]

36. Israelachvili, J.N. (Ed.) 4-Interactions Involving Polar Molecules. In Intermolecular and Surface Forces, 3rd ed.; Academic Press: San Diego, CA, USA, 2011; pp. 71-90.

37. Weaver, J.H.; Frederikse, H.P.R. Crc Handbook of Chemistry and Physics; CRC Press: Boca Raton, FL, USA, 1977.

38. Ruan, Y.; Zhu, Y.; Zhang, Y.; Gao, Q.; Lu, X.; Lu, L. Molecular Dynamics Study of $\mathrm{Mg}^{2+} / \mathrm{Li}^{+}$Separation via Biomimetic Graphene-Based Nanopores: The Role of Dehydration in Second Shell. Langmuir 2016, 32, 13778-13786. [CrossRef]

39. Zhu, Y.; Ruan, Y.; Zhang, Y.; Chen, Y.; Lu, X.; Lu, L. Mg ${ }^{2+}-$ Channel-Inspired Nanopores for $\mathrm{Mg}^{2+} / \mathrm{Li}^{+}$Separation: The Effect of Coordination on the Ionic Hydration Microstructures. Langmuir 2017, 33, 9201-9210. [CrossRef]

40. Wu, H.; Lin, Y.; Feng, W.; Liu, T.; Wang, L.; Yao, H.; Wang, X. A novel nanofiltration membrane with [MimAP][Tf $\left.{ }_{2} \mathrm{~N}\right]$ ionic liquid for utilization of lithium from brines with high $\mathrm{Mg}^{2+} / \mathrm{Li}^{+}$ratio. J. Membr. Sci. 2020, 603, 117997. [CrossRef] 
41. Xu, W.; Liu, D.; He, L.; Zhao, Z. A Comprehensive Membrane Process for Preparing Lithium Carbonate from High Mg/Li Brine. Membranes 2020, 10, 371. [CrossRef] [PubMed]

42. Zhong, J.; Lin, S.; Yu, J. Lithium recovery from ultrahigh $\mathrm{Mg}^{2+} / \mathrm{Li}^{+}$ratio brine using a novel granulated Li/Al-LDHs adsorbent. Sep. Purif. Technol. 2021, 256, 117780. [CrossRef] 